\title{
29. DATA REPORT: DEPTH AND DENSITY CORRECTIONS FOR LEG 150 SHIPBOARD GRAPE DATA ${ }^{1}$
}

\author{
Bryce W. Hoppie ${ }^{2}$
}

\begin{abstract}
Shipboard gamma-ray attenuation porosity evaluator (GRAPE) records from Ocean Drilling Program (ODP) Leg 150 contain inaccuracies in both depth and density caused by pervasive gas expansion voids and other coring disturbances. This paper describes the sequential procedure used to correct Leg 150 GRAPE data and presents corrected GRAPE data for Holes 902D, 903A, 904A, and 906A.

Corrections to shipboard GRAPE depth records were made for voids and for measurements taken from beyond the end of a section. Corrections to shipboard GRAPE densities were made for (1) narrow core diameters, (2) saline pore fluids, and (3) drill slurry. Records of voids and partially filled voids are identified by implementation of a minimum wet bulk density cutoff obtained from Leg 150 gravimetric density measurements. Records failing to meet the minimum density criterion are identified, tallied, and subtracted from the shipboard GRAPE data on a core-by-core basis. Density corrections for undersized core and for the Compton mass attenuation coefficient of pore-filling fluid are taken from earlier works; a new deterministic method of correcting for drill slurry is derived. Corrected data are shown to closely match gravimetric and downhole log bulk density records and visual estimates of depth corrections.

Results will be useful to sedimentologists, biostratigraphers, and geophysicists using Leg 150 data. Future physical properties specialists working in gassy sediments should find this work of particular interest.
\end{abstract}

\section{INTRODUCTION}

Drilling on Leg 150 began the process of documenting the continental margin record of the Oligocene-Holocene "Icehouse World" through acquisition of high-resolution chrono- and sequence-stratigraphic data, and characterization of facies variations associated with sea-level oscillations. Five sites were drilled on the New Jersey Margin approximately $180 \mathrm{~km}$ east-southeast of Atlantic City, New Jersey (Fig. 1).

High-resolution (2-cm sampling interval) wet bulk density measurements from the gamma-ray attenuation porosity evaluator (GRAPE) will forward the goals of Leg 150 in several ways:

1. GRAPE data may assist correlation among cores, downhole logs, measurements made on cores, and between holes and sites.

2. GRAPE data are strongly related to lithologic variation and, therefore, may serve as an indicator of relative sea-level changes.

3. The high-resolution character of GRAPE data, when coupled with chronostratigraphic data, may provide superior estimates of sediment accumulation rates especially with respect to Pleistocene glacial-interglacial cycles.

4. The nearly continuous record of wet bulk densities provided by the shipboard GRAPE measurements may provide additional chronostratigraphic information through time-series analyses.

Shipboard GRAPE records from Leg 150 have several significant inaccuracies associated with their depth and density data. The inac-

'Mountain, G.S., Miller, K.G., Blum, P., Poag, C.W., and Twichell, D.C. (Eds.), 1996. Proc. ODP, Sci. Results, 150; College Station, TX (Ocean Drilling Program).

Earth Sciences Department, University of California, Santa Cruz, CA 95064. U.S.A. bwhoppie@cats.ucsc.edu curacies are most prevalent in advanced piston coring (APC) cores where the percussive style of core cutting prohibited the escape of in situ biogenic gas. Gas trapped in the core expanded at the surface and caused the formation of voids ranging from micrometer-scale up to $20 \mathrm{~cm}$ in length; many cores contained multiple voids (see Shipboard Scientific Party, 1994b). Core sections were measured with expansion gaps still in place, causing errors in the measurement of both density and depth.

Gas expansion caused some cores to expand up to an additional $40 \%$ of their original length. Although up to $10 \%$ (Hamilton, 1971) of this over-recovery is the result of normal rebound, the rest is the direct result of gas expansion. Because gas voids are not closed before GRAPE measurements are taken, the problem of over-recovery is directly translated into errors in the depth record of shipboard GRAPE data. The distribution of voids in sections and cores is not uniform; thus, a simple linear correction is not possible. Furthermore, the GRAPE depths are even inconsistent with the depths of gravimetric density. Many voids were closed by shipboard technicians after GRAPE measurements but before photography and sampling by other shipboard scientists. Thus, GRAPE densities cannot always be correlated with other measurements and observations of the core.

Voids are also a cause of inaccuracies in GRAPE densities. Besides the obviously errant measurements of complete voids in the shipboard GRAPE data, many measurements include averages of core and void. Other measurements are incorrect because they were made beyond the end of individual sections, or within "flow-in" sections, or because they include significant drill slurry.

The inaccuracies outlined above limit the usefulness of the shipboard data for all of the aforementioned goals. They must be understood and properly corrected before further studies using the GRAPE data can begin. This report describes the sequential process of correcting GRAPE depth and density measurements acquired during Leg 150. Raw GRAPE data acquisition is reviewed, corrections are listed, and comparisons to gravimetric and log bulk densities are made. 


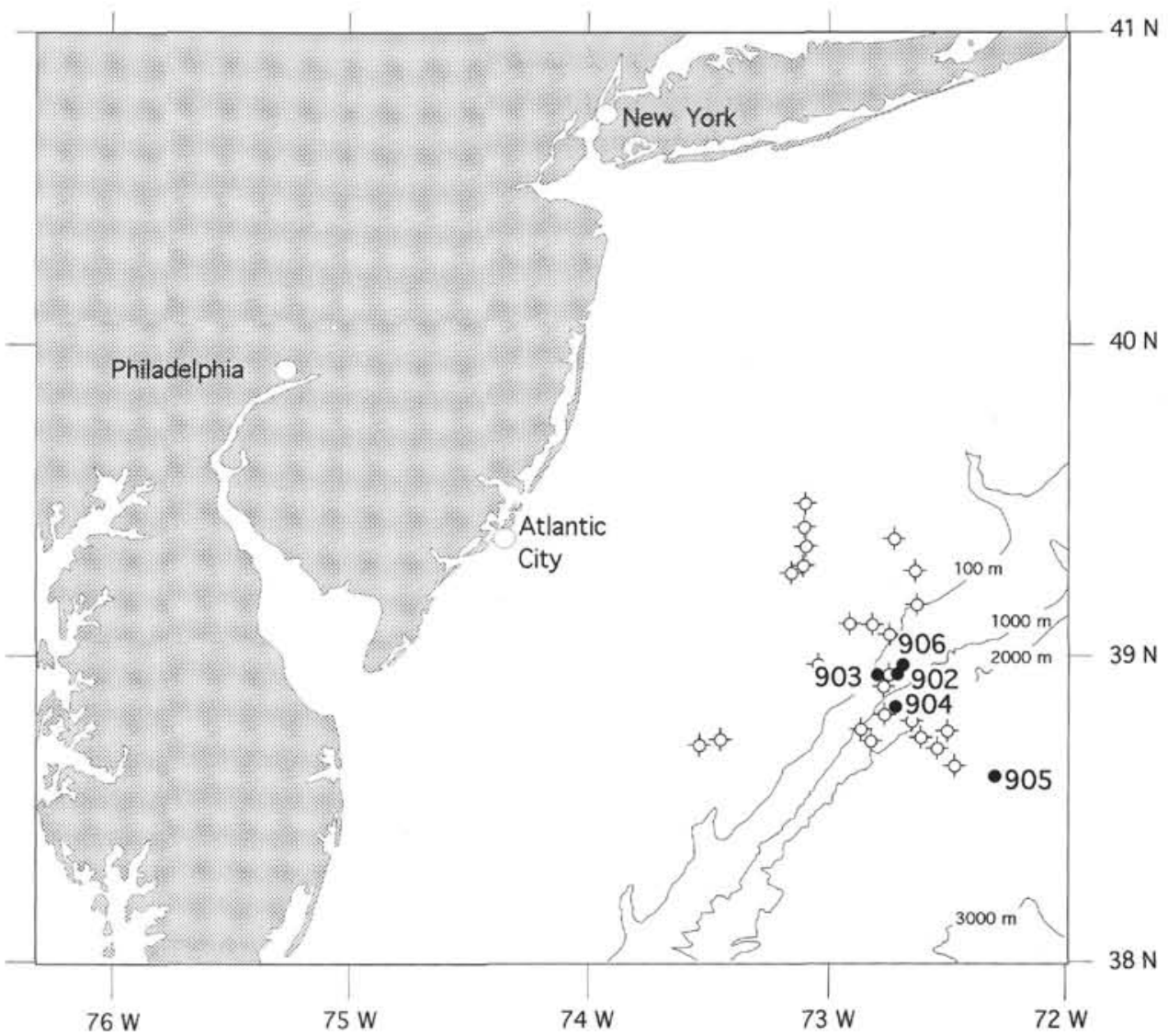

\section{DATA ACQUISITION}

The GRAPE detection device (Evans, 1965; Evans and Cotterell, 1970) is mounted on the shipboard multisensor track (MST) system, which feeds whole cores sections through the device at a specified rate. Gamma-rays emitted from a shielded cesium $\left({ }^{137} \mathrm{Cs}\right)$ source are collimated into a narrow beam, which passes through the diameter of the whole core, and are measured by a scintillation detector on its opposite side. At time intervals specified by the MST operator, the transmitted intensities of gamma rays are measured and related to bulk density by

$$
\rho_{b}=\frac{1}{\mu a} \ln \left[\begin{array}{l}
I_{0} \\
T
\end{array}\right],
$$

where $\rho_{b}=$ wet bulk density, $\mu=$ the Compton mass attenuation coefficient of quartz $\left(\mathrm{cm}^{2} / \mathrm{gm}\right), d=$ the diameter of the core $(\mathrm{cm}), I_{O}=$ the intensity measured in the absence of core, and $I=$ transmitted intensities.

The principal assumption needed to use this method to calculate wet bulk density is that $\mu$ is known and does not vary with lithology or pore fluid. Other implicit assumptions are that (1) the gamma-ray source emits gamma rays constantly with energies between 0.2 and $3.0 \mathrm{MeV}$, (2) electron and bulk densities are directly related, (3) core diameter and core-liner thickness are uniform and well defined, and (4) the apparatus is operating within its specified calibrations. Previous work both by ODP and others has shown that these assumptions are met for the shipboard device and the materials routinely analyzed during ODP operations (Evans, 1965; Evans and Cotterell, 1970; Whitmarsh, 1971); as described elsewhere, GRAPE calibrations were practiced throughout Leg 150 to ensure the device's hardware operated within its specified parameters (Shipboard Scientific Party, 1994a).
Several other practical considerations must also be met before wet bulk densities from GRAPE measurements accurately reflect the wet bulk densities of recovered lithologies: The material being analyzed must be free of drilling slurry, the gamma-ray beam must be located at the exact diameter of the core, the beam must be completely within core material and not partially exposed to void space within the core, and the bulk density must be corrected for pore fluid densities other than $1 \mathrm{~g} / \mathrm{cm}^{3}$. The assurance that the first two of these qualifications are met is not straightforward. Because the core is hidden from view by the core liner and the GRAPE lead shielding, indirect means (discussed later) must be used to determine whether the core is free of slurry and void spaces. The correction for fluid density is straightforward and can be easily applied.

When all of the aforementioned conditions are met, wet bulk densities from GRAPE measurements are accurate to within $\pm 11 \%$ of comparable gravimetric density analyses (Boyce, 1976). However, the practical considerations listed previously were not incorporated into the shipboard processing of the GRAPE data and serve as the focus of this report.

Leg 150 shipboard scientists collected data on all sectioned cores from all sites although core catchers were measured only in rare cases. During Leg 150, GRAPE measurements were made every 2-2.5 $\mathrm{cm}$ along the core. Several sections, particularly from APC cores, could not be processed as core liner damage caused them to become lodged in the GRAPE.

\section{DEPTH AND DENSITY CORRECTIONS}

Correction of shipboard GRAPE data was performed in a sequential process whereby density and depth records were successively and iteratively corrected. Each correction is discussed below in the order in which it was performed on the Leg 150 shipboard GRAPE data. 


\section{Preliminary Corrections}

The first correction of shipboard data was the removal of all redundant records. After installation of the new MST natural gammaray detector, cores in the MST routinely stopped in the GRAPE analyzer for extended sampling periods. Because GRAPE measures wet bulk density as a function of time and not distance, GRAPE results intermittently have 30 or 40 measurements (as counted in the shipboard GRAPE data files) at the same depth. Redundant records were removed before the application of the slurry volume correction developed specifically for this project. This is because the slurry volume correction uses a comparison of gravimetric and GRAPE wet bulk densities and therefore requires a statistically consistent GRAPE record. Thus, GRAPE records were scanned and only the first density and depth pair for a depth with multiple measurements were kept; all others were deleted.

A second preliminary correction involves core intervals identified by shipboard sedimentologists as flow-in. All data corresponding to flow-ins were deleted. GRAPE data from flow-in intervals are meaningless; the sediments are completely disturbed and primary physical properties are destroyed.

\section{Density Corrections}

The first correction applied to GRAPE densities concerns core diameter. GRAPE measurements, as shown above, are used to calculate density given several parameters including the core diameter. Consequently, if core diameters vary from that for which the GRAPE is calibrated, resulting GRAPE densities will be in error. Core diameters, especially from extended core barrel (XCB) and rotary core barrel (RCB) drilling in the deeper portions of Leg 150 drill holes had narrow $(<6.61 \mathrm{~cm})$ core diameters. Narrow core diameters cause GRAPE densities to be incorrectly lowered. Therefore, I first corrected shipboard GRAPE density data for narrow core diameters as recommended by Boyce (1976):

$$
\mathrm{GRAPE}_{\text {adjusted }}=\mathrm{GRAPE}_{\text {original }} \times(\text { actual diameter }[\mathrm{cm}] / 6.61) .
$$

Note that this correction requires the space between the core and liner to be filled with air (i.e., no liquids), and an accurate independent estimate of core diameter. The first requirement is usually met in cores requiring this correction; the narrow diameters of the core sections easily allow the liquids in this space to drain out of the core liners. For the second requirement, shipboard physical properties specialists measured some cores and core liners with a hand-held caliper, the sampling interval was insufficient(often one per section) to be useful for this analysis. Core photographs were therefore used to augment the caliper data. Core diameters were measured from shipboard photographs of cores with narrow diameters and compared to caliper measurements taken by shipboard scientists. Differences between the two methods were generally small, approximately $10 \%$; however, by Equation 2 the amount of error in measurement of core diameters is directly translated to errors in GRAPE density, and great care was taken to characterize core diameters as accurately as possible before the application of this correction.

The second correction to GRAPE density data involves core fluid properties. Density is measured by the attenuation of gamma rays through solid and fluid material in the core (Evans, 1965; Evans and Cotterell, 1970). Calculations used to generate shipboard GRAPE data use the attenuation coefficient of quartz exclusively. Use of this coefficient results in little error if the core is composed completely of solid minerals (Shipboard Scientific Party, 1972; Whitmarsh, 1971); however, as a $10 \%$ difference in attenuation coefficients exists between quartz and seawater, a correction must be applied to shipboard GRAPE density data to account for abundant interstitial fluids in sedimentary rocks. Therefore, the following simple correction (Evans,
1965; Evans and Cotterell, 1970; Boyce, 1976; Whitmarsh, 1971) was applied to Leg 150 shipboard GRAPE density data to better estimate true wet bulk density:

$$
\rho_{b}=\left(\left[\rho_{b}-\rho_{f c}\right]\left[\rho_{g}-\rho_{f}\right] /\left[\rho_{g c}-\rho_{f c}\right]\right)-\rho_{f}
$$

where $\rho_{b}=$ adjusted wet bulk density, $\rho_{f}=$ fluid density of sea water, $\rho_{g}=$ grain density of quartz, and $\rho_{f c}, \rho_{g c}=$ fluid and grain densities as read by the GRAPE.

A third GRAPE density correction, discussed by Boyce (1976), is for core-liner slurry volume. Application of this correction is not straightforward and is discussed thoroughly later in this paper.

\section{Depth Corrections}

Correction of the shipboard GRAPE depths is based on the assumption that voids can be detected by the GRAPE density measurement, that is, GRAPE densities within a void will have a density below some minimum cutoff value that indicates the measurement took place within a void (at least partially) filled with water or gas. Voids mark expansion of the core, and hence the depth record of core recovery; as noted earlier, these voids are detrimental to the accuracy of the GRAPE data and must be removed. Therefore, GRAPE depths corresponding to density measurements below the minimum cutoff can were identified, tallied, and subtracted from the shipboard GRAPE depth record to correct the record for voids.

An obvious minimum cutoff value is $1.0 \mathrm{~g} / \mathrm{cm}^{3}$, the approximate density of water. Many voids, however, consist of mixed void-filling gas or fluid and small amounts of displaced core material (hereafter referred to as partially filled voids). Therefore, a new minimum cutoff, one more sensitive to partially filled voids than the $1.0 \mathrm{~g} / \mathrm{cm}^{3}$ of water-filled voids, was necessary. The new density cutoff was obtained by incorporating gravimetric wet bulk densities. A description of how gravimetric wet bulk densities were used to obtain a new minimum density cutoff for editing GRAPE depth records is provided in the next several paragraphs.

Gravimetric wet bulk densities were immediately recognized as a possible means of estimating the density cutoff. Rigorous depth shifting of downhole log data and comparison with gravimetric densities indicated that core wet bulk densities needed no correction to match in situ bulk densities measured by downhole logging tools (see Hoppie, this volume). That is, gravimetric wet bulk densities are a good estimate of the true wet bulk densities of the sediment. They may thus be scanned to find a minimum wet bulk density of undisturbed core distinct from densities of partially filled voids.

Gravimetric wet bulk densities were scanned to find the lowest average wet bulk density of sediments recovered during Leg 150 . This value was found to be $1.42 \mathrm{~g} / \mathrm{cm}^{3}$; however, because GRAPE measurements are subject to statistical variation, and the shipboard software responsible for gathering raw GRAPE data does not correct for the pore-fluid corrections shown in Equation 2, this is not the minimum cutoff value of shipboard GRAPE data. The GRAPE density cutoff was determined by first adjusting the minimum gravimetric sediment density by the inverse of Equation 2. This calculation raised the minimum GRAPE density cutoff indicated by true wet bulk densities from undisturbed core to $1.5 \mathrm{~g} / \mathrm{cm}^{3}$. The second adjustment lowered the cutoff value by $11 \%$, which is the statistical variability shown to exist within the GRAPE apparatus by Boyce (1976). Using this lowered value ensures that no depth segments are removed because of known variability in the detection apparatus. Thus, the cutoff value to be applied to the GRAPE densities was lowered to $1.35 \mathrm{~g} / \mathrm{cm}^{3}$.

Density data failing to meet the minimum cutoff were removed from the shipboard data. Corresponding depth increments were tallied by section and core, and then subtracted from the shipboard GRAPE depth record. Tallies were reset at the top of each core; this 
Figure 2. GRAPE depth record corrections as a function of core and depth for the upper $160 \mathrm{mbsf}$ of Hole 902D. Depth corrections are the cumulative sum of individual GRAPE analyses (approximately $2-\mathrm{cm}$ sampling interval) failing to meet the minimum density cutoff criteria. Horizontal bars represent the uncorrected length of each core. Total depth corrections indicated by this procedure compare to within $10 \%$ of visual estimates from core photographs.

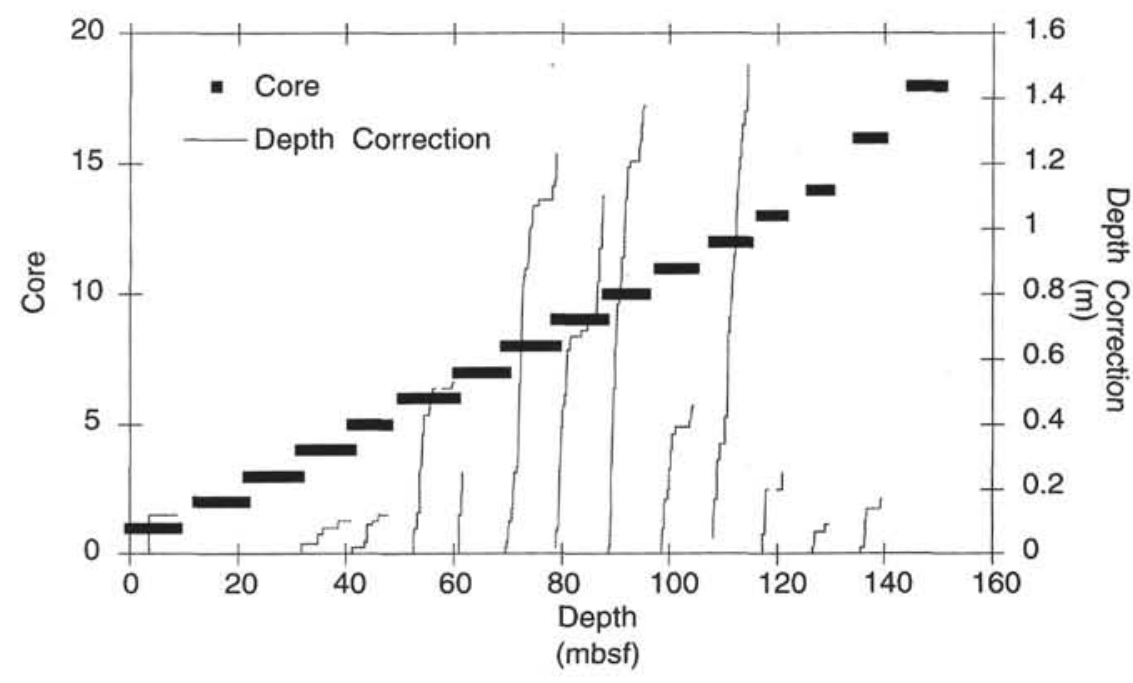

assumes the driller's depth record is accurate to the top of each new core and that GRAPE depths are only incorrect within each core. An example of a depth-correction tally for Hole 902D is presented in Figure 2.

The void correction also works to remove MST operator errors and errant densities measured when the GRAPE detector is (mistakenly) set to measure section lengths beyond the actual length of the section. Generally, MST operators (of which I was one) are very conscientious about setting the length parameter properly; however, many instances occurred where an additional measurement beyond the end of a section was inadvertently measured by the GRAPE. The cutoff filter described above adequately identified and removed these errant data.

\section{Drill Slurry Corrections}

The final correction required by shipboard GRAPE data is for the volume of slurry lying between the core and core liner. This slurry is usually of radically different wet bulk density than the sediments in the core because it consists of sediments ground during coring and loosely mixed with drilling fluids. As such, sections with significant drilling slurry will have reduced GRAPE densities not representative of the true wet bulk density of the solid core.

The correction for slurry is the most difficult. It requires an a priori knowledge of both the volume and density of the slurry. These data were not available for Leg 150. Therefore, I chose to correct GRAPE densities by fitting GRAPE data to gravimetric density data and adjusting all GRAPE data with the resulting correlation coefficients. Gravimetric data were used because they are unaffected by slurry contamination: shipboard scientists selectively exclude slurry from gravimetric samples. Gravimetric density data also shows close correspondence to downhole log wet bulk density data; thus, this "fitting" exercise should create GRAPE wet bulk densities approximating in situ wet bulk density.

Correction of GRAPE data by regression against gravimetric wet bulk density data requires that the two data sets represent the exact same sediment. This requires that GRAPE and gravimetric measurements be (1) taken at exactly the same depth interval and (2) sample exactly similar sediment volumes.

The first condition was met by selecting gravimetric and GRAPE data from intervals without gas voids, interpolating and resampling the GRAPE data at depths of gravimetric analysis, and cross-plotting the two records. It is important to note that only GRAPE and gravimetric data from intervals free of voids were used. If data from intervals with voids were used, an additional assumption that GRAPE and gravimetric data were correctly adjusted to the same depth would be necessary. Because several intervals free of voids existed at Sites 902,904 , and 906, it was not necessary to use GRAPE and gravimetric data susceptible to depth related errors.

The second condition, that they represent similar sediment volumes, is admittedly not met. This is because of differing sampling volumes between the two methods. GRAPE samples a pencil-like volume of sediments $2-3 \mathrm{~mm}$ in diameter by $6.61 \mathrm{~cm}$ in length (Boyce, 1976), whereas gravimetric analyses sample a $10-\mathrm{cm}^{3} \mathrm{sam}-$ ple taken by scooping out sediments within a $2-\mathrm{cm}$-thick interval of a split core (Shipboard Scientific Party, 1994a). Given the imprecisions of both measuring techniques and the close proximity of the two measurements, however, the sampled volumes of sediment from the two methods are as close as possible. I assume the difference is inconsequential.

Because of differences in the drilling and recovery of APC and $\mathrm{XCB}$ cores, two different corrections were derived. APC cores are cut by a percussive method of firing an empty core barrel into soft sediments. Thus, the amount of slurry surrounding these cores is generally very small, consisting of a small amount of soft sediment and drilling fluid smeared along the outside of undisturbed sediments. In contrast, $\mathrm{XCB}$ cores are cut by rotation of the core bit while drilling fluids flush and lubricate the assembly and area at the point of cutting. As such, considerable slurry is often generated, which subsequently fills the space between undisturbed core sediments and the core barrel. Comparison of cross-plotted results from the separate regression of GRAPE and gravimetric data from APC and XCB cores confirm the choice of separate regressions (see Fig. 3). GRAPE data requires far less correction in APC cores than in XCB cores to match corresponding gravimetric data.

It is worthy of note that this final correction affects all other adjustments. The fitting of GRAPE to gravimetric data overrides individual diameter and fluid corrections recommended by Boyce (1976) and forces GRAPE data to match gravimetric data. For this reason, I chose to apply this correction last which, causes the correction to concentrate on the problem of slurry volume in GRAPE data.

\section{RESULTS}

The aforementioned corrections adjusted both shipboard GRAPE density and depth data. Corrections were applied to all holes except 905A; final results for Holes 902D, 903A, 904A, and 906A are presented in Figures 4 through 7, which show "before and after" depth plots of Leg 150 GRAPE data. Note that the final results were pro- 
A

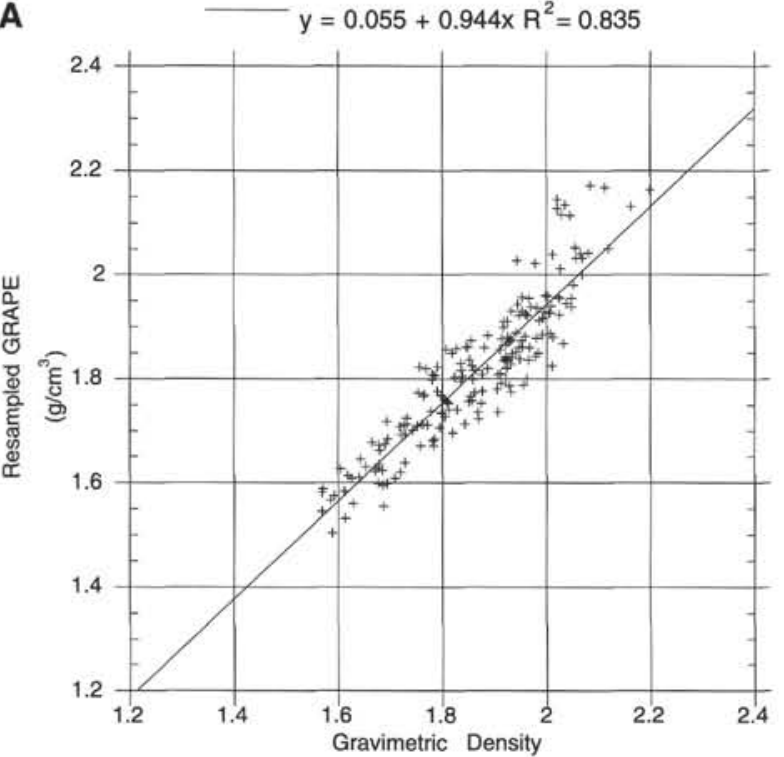

$\left(\mathrm{g} / \mathrm{cm}^{3}\right)$

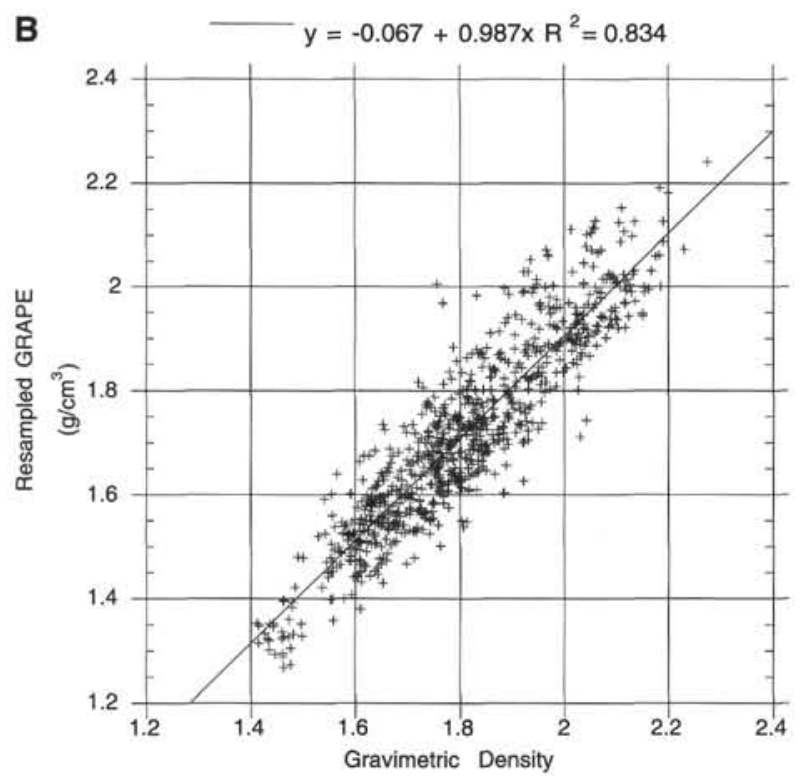

$\left(\mathrm{g} / \mathrm{cm}^{3}\right)$

Figure 3. Cross plots of GRAPE and gravimetric wet bulk density data used for determining the amount of slurry-volume correction needed for GRAPE measurements on Leg 150 (A) APC and (B) XCB cores. Slopes for both coring methods approach 1 and thus imply that the amount of slurry surrounding cores is fixed and depends strongly on the method of coring.

cessed through a 9-point (approximately $20 \mathrm{~cm}$ ) Pascal's Rule centerweighted moving average $(1,8,28,56,70,56,28,8,1)$ to remove some of the noise in the data. The purpose of filtering the data is to produce results ready for use by biostratigraphers, stratigraphers, and geophysicists. Filtering alone does improve the GRAPE data; GRAPE data that is simply filtered is still contains incorrect density and depth data.

The depth corrections caused an overall shortening of GRAPE records within individual cores recovered during Leg 150. Although the overall difference between corrected and uncorrected GRAPE depth records for an entire hole is much less $1 \%$, the correction within any given core (especially in APC cores) may be up to $16 \%$ (approximately $1.5 \mathrm{~m}$ ). Figure 2 illustrates the depth adjustments required for the upper $150 \mathrm{mbsf}$ of Hole 902D. Corrections were applied to Holes 902A-902D, 903A-903B, 904A, and 906A. Few intervals from deeper XCB and RCB cores were removed, thus verifying the application of the diameter correction before application of the minimum density cutoff.

Verification of the accuracy of the depth-shifting results is difficult. Results were checked against hand-measured estimates made from core photographs. Estimates from the two methods agreed to within $10 \%$ in most cases, and where results did not agree, there was evidence that voids may have been closed before photographing the cores.

Density corrections are dramatic. Shipboard GRAPE results were riddled with many errant density measurements and their mismatch to gravimetric data was noted (Shipboard Scientific Party, 1994c). Corrected GRAPE densities closely correspond to shipboard and shore-based gravimetric and downhole log wet bulk densities (Fig. 8 ). Rigorous checking was not undertaken; the close correlation between gravimetric and GRAPE density data through intervals used to derive the correction function implies the match should be excellent.

The results also exhibit much less variability and ease the identification of significant density transitions and cycles (see Christensen et al., and Vescei and Hoppie, this volume). As an example, shipboard scientists used shipboard GRAPE data to correlate GRAPE densities to SPECMAP oxygen isotopic trends for the identification of Pleistocene glacial-interglacial cycles (Shipboard Scientific Party, 1994a). New GRAPE data will clarify several questionable correlations in that work and provide better depth estimates for comparison of glacial versus interglacial sediment accumulation rates.

\section{DISCUSSION AND SUMMARY}

The work discussed in this paper produces GRAPE depths and densities with improved accuracy over original shipboard GRAPE data. Results are most useful to scientists of Leg 150 interested in high-resolution studies. Depth differences within individual cores can be significant (up to $16 \%$ ) and will affect calculated sedimentation rates for intervals within individual cores. In contrast, depth differences over scales of tens of meters or more are insignificant.

Results are also useful to sedimentologists interested in using the corrected (and consistent) GRAPE records for interhole and intersite correlation. Biostratigraphers and sedimentologists may also find the new GRAPE records useful for time-series analyses. The new records not only provide better depth estimates, but also eliminate errant variabilities in the record and thus makes the identification of significant spectral features much easier. Geophysicists using the GRAPE record for reflectivity profiles may also benefit from the new GRAPE density. Because many of the largest density contrasts were caused by adjacent void and core GRAPE analyses, reflectivity profiles constructed from the original data may indicate seismic reflectors at depths where no reflector lies in the subsurface.

Finally, the results presented here should be of use to future physical properties specialists working on Legs where gassy cores are recovered. This report can be used as a recipe for the identification and correction of potential errors in the shipboard GRAPE record. The method utilizes many corrections discussed in earlier reports (i.e., Evans, 1965; Evans and Cotterell, 1970; Whitmarsh, 1971; Boyce, 1976), but also has a deterministic correction derived specifically for data from Leg 150. Although this means the specific corrections used in this paper cannot be applied to other GRAPE data unthinkingly, the procedure of deriving requisite corrections is thoroughly discussed and can be replicated when necessary. The slurry volume correction is recommended as an improvement over that discussed by 

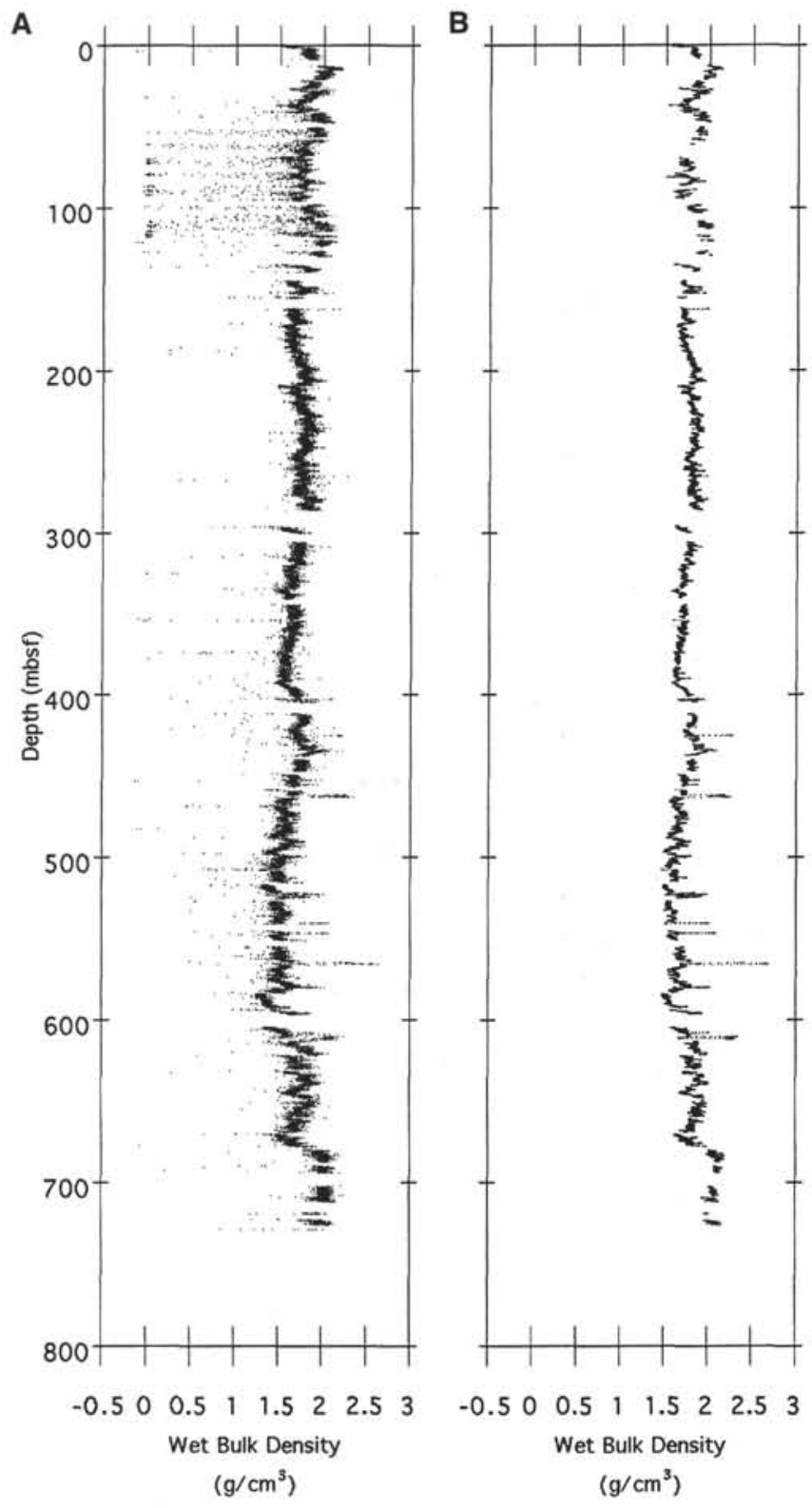

Figure 4. Depth plots of (A) raw and (B) corrected GRAPE data from Hole 902D.
Boyce (1976). Boyce's method requires an a priori knowledge of slurry volume and density. These data simply are not available for most ODP legs and thus, the deterministic method of matching gravimetric to GRAPE densities represents a more pragmatic approach to correcting GRAPE data.

\section{ACKNOWLEDGMENTS}

I thank C.S. Fulthorpe, J.M. Lorenzo, A. Vecsei, T. Kimura, and the many Marine Laboratory Specialists of Leg 150 for their assistance in acquiring shipboard GRAPE data. P. Blum fostered my interest in correcting the GRAPE data, and I thank him for planting the bug. Editorial comments by P. Blum and a careful review by R. Whitmarsh significantly improved this manuscript, and I sincerely thank both of them. This research was supported by ODP Grant No. 15020783A.

\section{REFERENCES}

Boyce, R.E., 1976. Definitions and laboratory techniques of compressional sound velocity parameters and wet-water content, wet-bulk density, and porosity parameters by gravimetric and gamma-ray attenuation techniques. In Schlanger, S.O., Jackson, E.D., et al., Init. Repts. DSDP, 33: Washington (U.S. Govt. Printing Office), 931-958.

Evans, H.B., 1965. GRAPE-a device for continuous determination of material density and porosity. Trans. SPWLA 6th Ann. Logging Symp., Dallas, 2:B1-B25.

Evans, H.B., and Cotterell, C.H., 1970. Gamma-ray attenuation density scanner. In Peterson, M.N.A., Edgar, N.T., et al., Init. Repts. DSDP, 2: Washington (U.S. Govt. Printing Office), 460-472.

Hamilton, E.L., 1971. Prediction of in-situ acoustic and elastic properties of marine sediments. Geophysics, 36:266-284.

Shipboard Scientific Party, 1972. Explanatory notes. In Laughton, A.S., Berggren, W.A., et al., Init. Repts. DSDP, 12: Washington (U.S. Govt. Printing Office), 24.

, 1994a. Explanatory notes. In Mountain, G.S., Miller, K.G., Blum, P., et al., Proc. ODP, Init. Repts., 150: College Station, TX (Ocean Drilling Program), $21-42$.

-, 1994b. Section 4: Cores. In Mountain, G.S., Miller, K.G., Blum, P., et al., Proc. ODP, Init. Repts., 150: College Station, TX (Ocean Drilling Program), 367-830.

, 1994c. Site 902. In Mountain, G.S., Miller, K.G., Blum, P., et al., Proc. ODP, Init. Repts., 150: College Station, TX (Ocean Drilling Program), 63-127.

Whitmarsh, R.B., 1971. Precise sediment density determination by gammaray attenuation alone. J. Sediment. Petrol., 41:882-883.

Date of initial receipt: 17 February 1995

Date of acceptance: 29 August 1995

Ms 150SR-029 


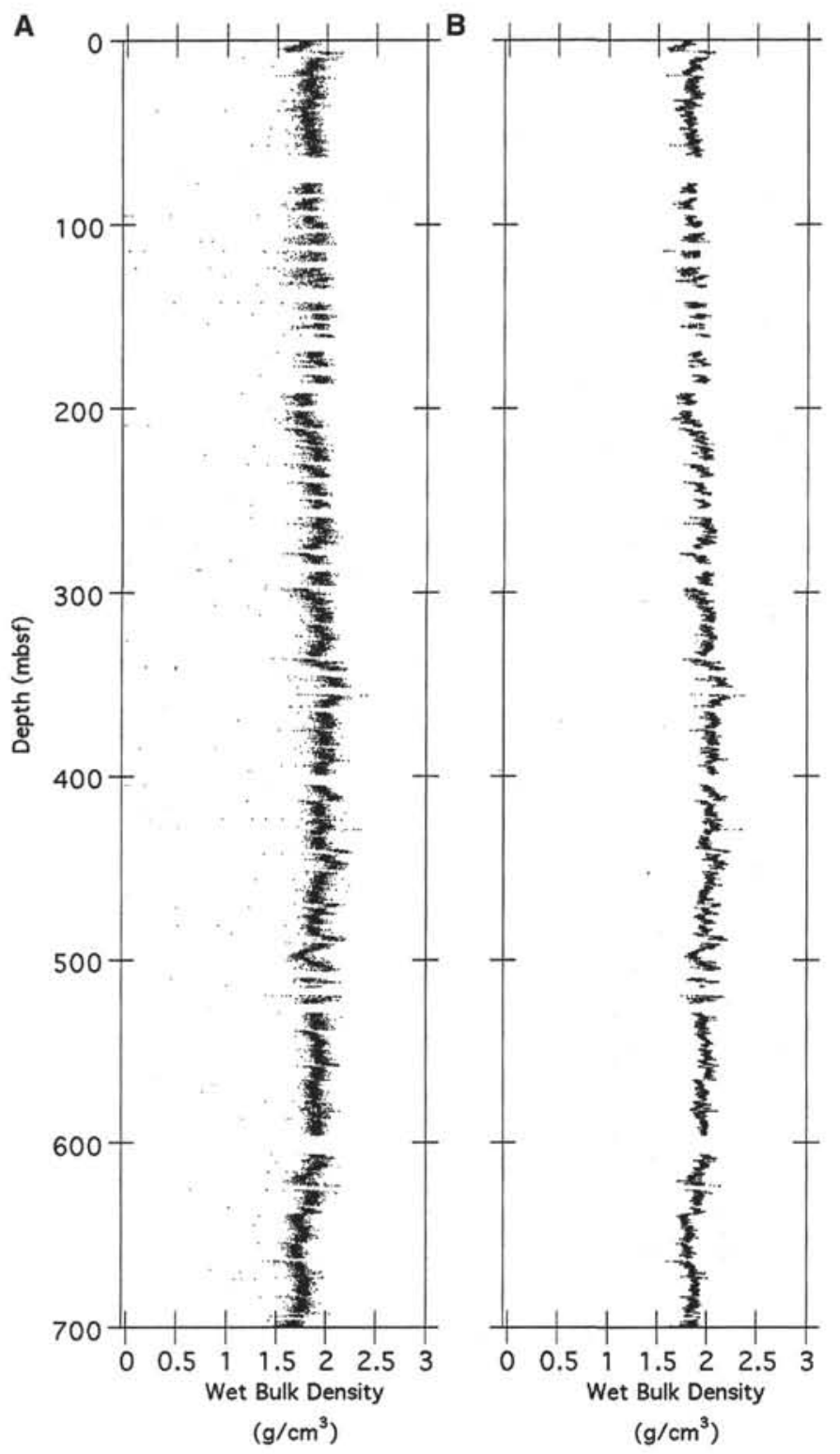

Figure 5. Depth plots of (A) raw and (B) corrected GRAPE data from Hole 903A.
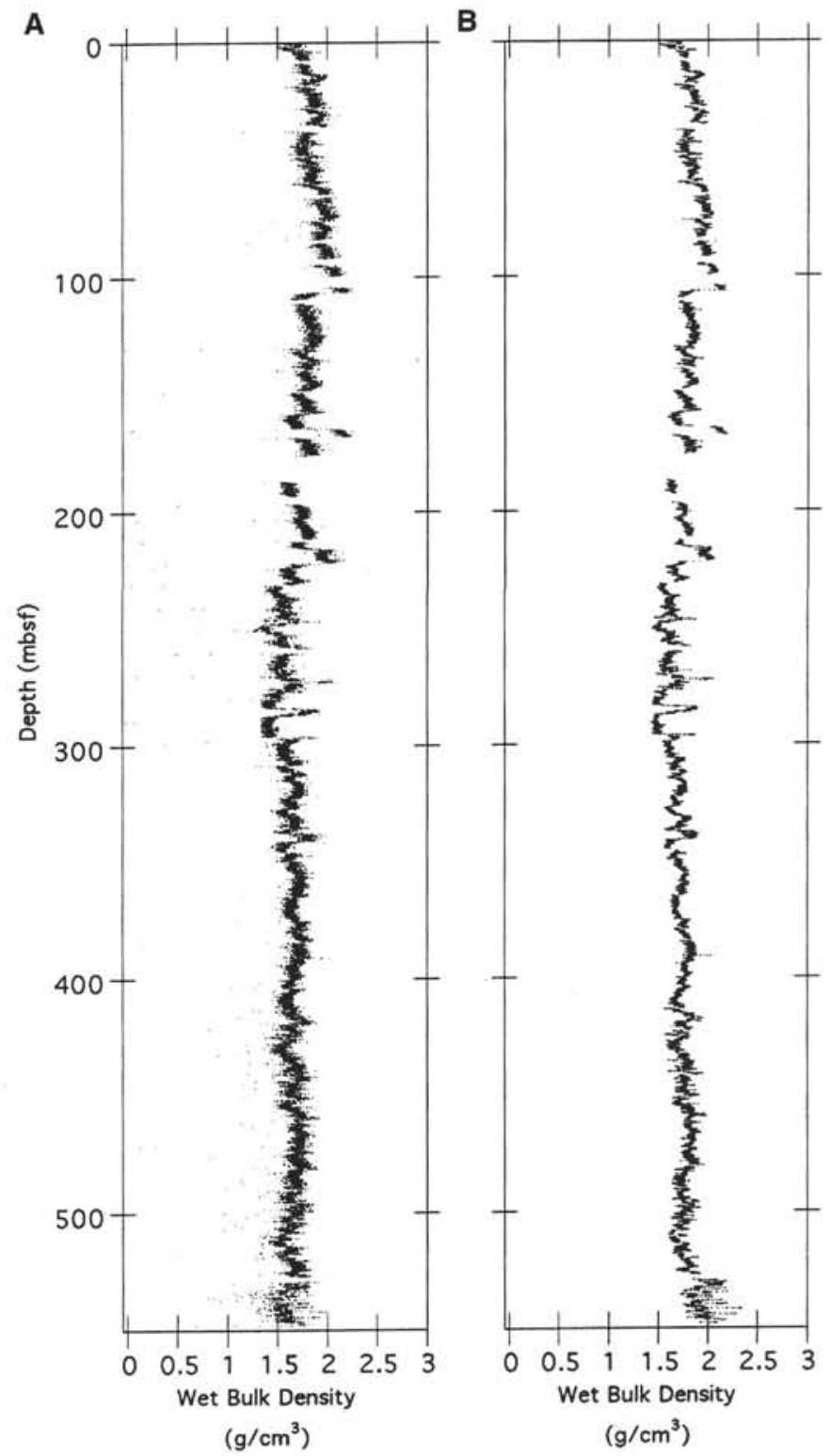

Figure 6. Depth plots of (A) raw and (B) corrected GRAPE data from Hole $904 \mathrm{~A}$. 
A

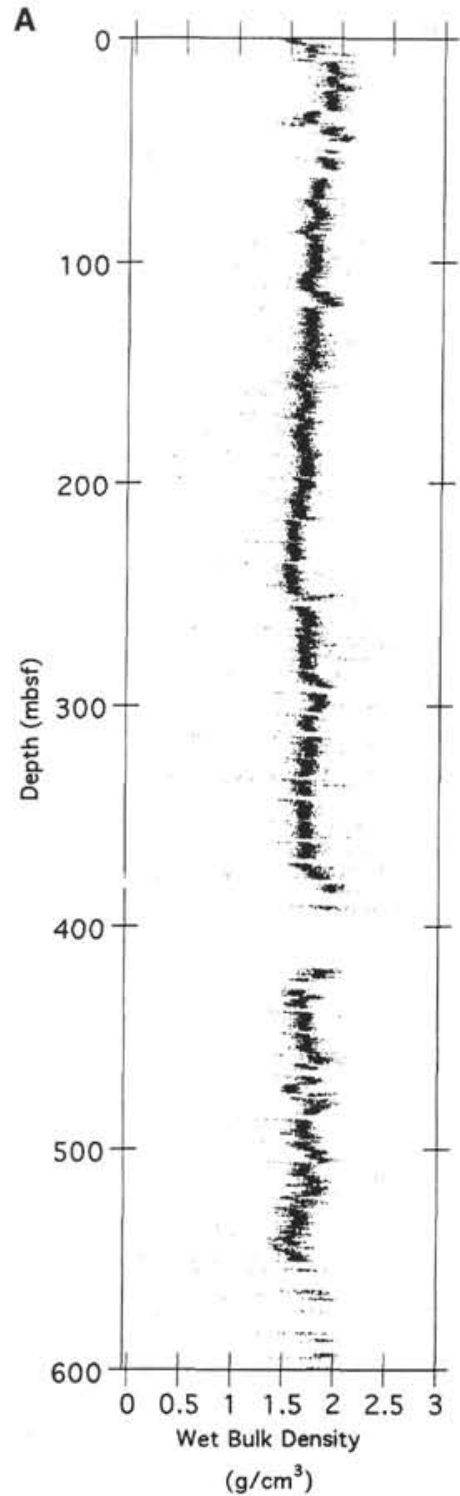

Figure 7. Depth plots of (A) raw and (B) corrected GRAPE data from Hole $906 \mathrm{~A}$.
B

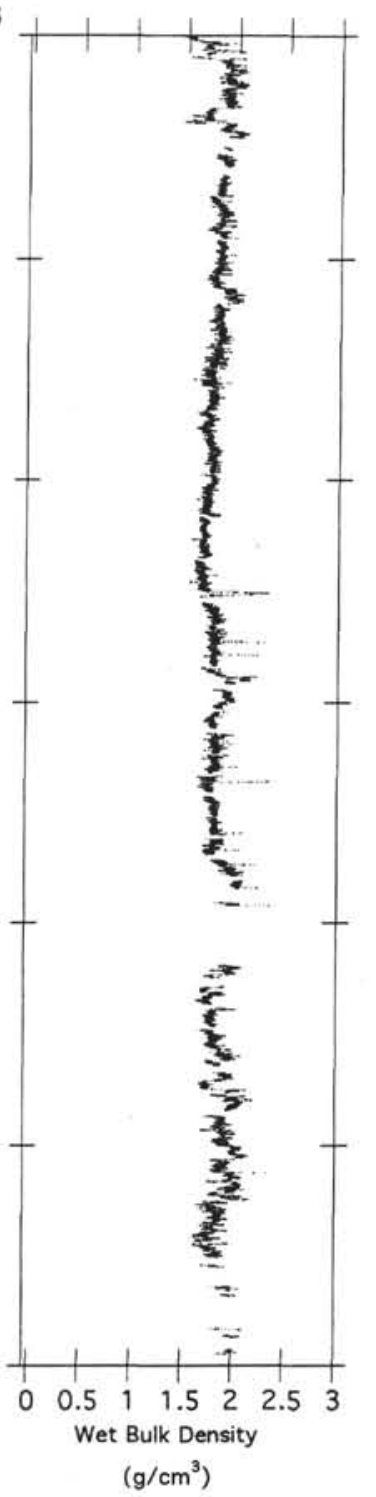

$\left(\mathrm{g} / \mathrm{cm}^{3}\right)$

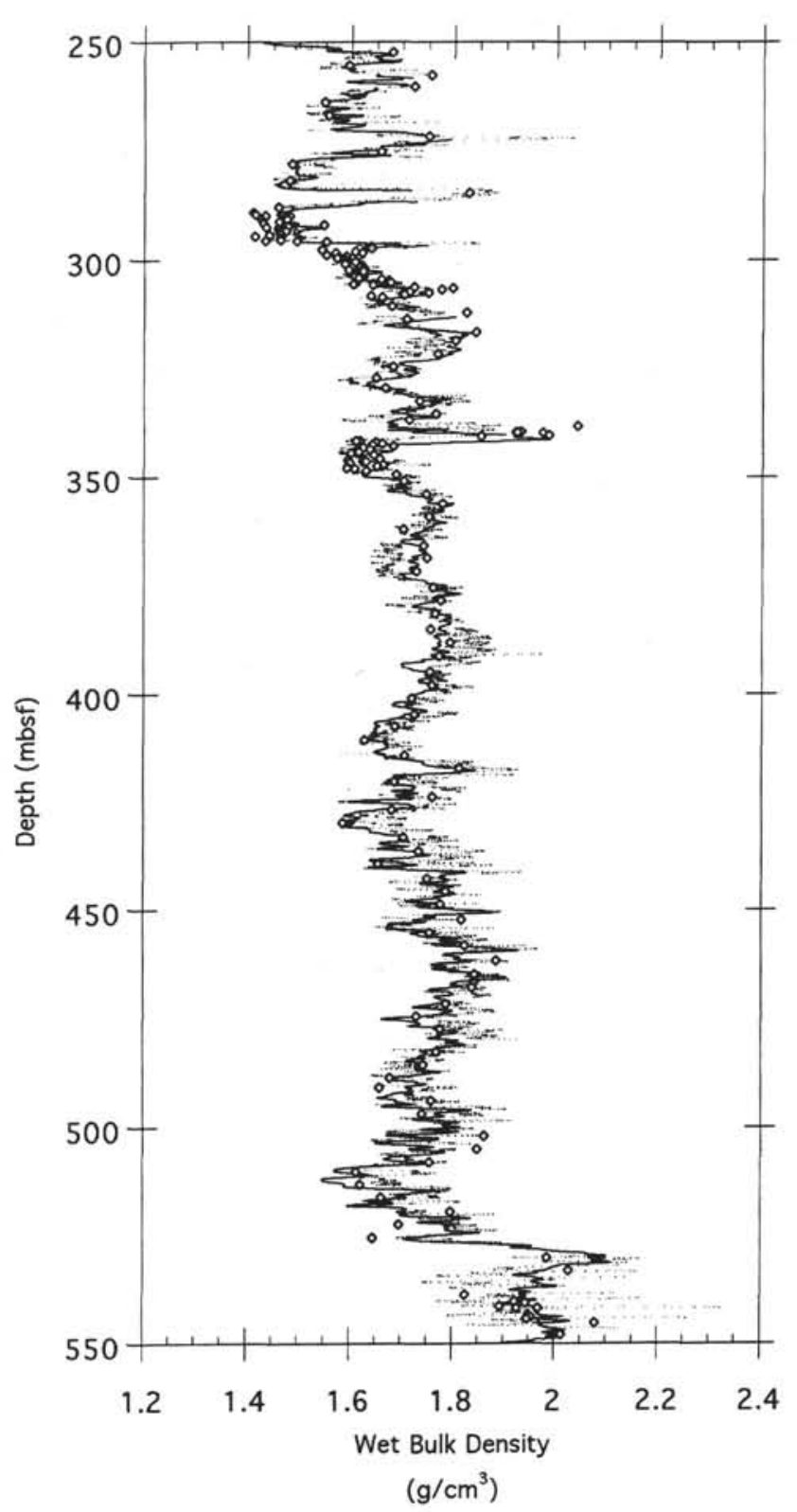

Figure 8. Depth plot of all wet bulk density data for Hole 904A. The solid line represents downhole log data whereas the diamonds and dots represent gravimetric and GRAPE data, respectively. The close correspondence of all three verifies the GRAPE corrections discussed in this paper. 